\title{
The rs738409 (I148M) Variant of the PNPLA3 Gene and Type 2 Diabetes in Yakutia
}

\author{
Lubov A. Sydykova, $\mathrm{PhD}^{1 *}$; Khariton A. Kurtanov, $\mathrm{PhD}^{2}$; Natalia V. Borisova, $\mathrm{PhD}, \mathrm{ScD}^{1}$; \\ Nadejda I. Pavlova, $\mathrm{PhD}^{2}$; Konstantin M. Stepanov, $\mathrm{PhD}, \mathrm{ScD}^{2}$; Sardana V. Markova, $\mathrm{PhD}^{1}$; \\ Albert D. Makarov, $\mathrm{PhD}^{1}$; Sardana N. Alekseeva, $\mathrm{PhD}^{1}$; Uliana D. Antipina, $\mathrm{PhD}^{1}$ \\ ${ }^{\prime}$ M. K. Ammosov North-Eastern Federal University \\ ${ }^{2}$ Yakut Science Center of Complex Medical Problems \\ Yakutsk, the Republic of Sakha (Yakutia), Russia
}

\begin{abstract}
The purpose of our research was to study the association of the PNPLA3 SNP rs738409 (C>G) with type 2 diabetes (T2D) in the Yakuts. The frequency distribution of alleles and genotypes of the PNPLA3 SNP rs738409 was in accordance with HWE. There were no statistically significant differences in the distribution of alleles and genotypes of the PNPLA3 SNP rs738409 between T2D patients and non-T2D patients $(P>0.05)$; the $\mathrm{G}$ allele and homozygous GG genotype prevailed in both groups. In T2D patients, a high frequency of the G allele (74.1\%) was found, with a predominance of the GG genotype $(58.5 \%)$. We also found that the mutant allele frequency is higher than in the studied populations of the world. Further studies with larger sample size are required to achieve sufficient statistical power to detect the association of the PNPLA3 SNP rs738409 with the development of $\mathrm{T} 2 \mathrm{D}$ in Yakut patients. (International Journal of Biomedicine. 2018;8(3):201-205.)
\end{abstract}

Key Words: type 2 diabetes $\bullet$ gene polymorphism $\bullet$ non-alcoholic fatty liver disease $\bullet$ Yakut population

\section{Abbreviations}

ALD, alcoholic liver disease; DM, diabetes mellitus; CHC, chronic hepatitis C; CVD, cardiovascular diseases; HCC, hepatocellular carcinoma; NASH, non-alcoholic steatohepatitis; NAFLD, non-alcoholic fatty liver disease; PNPLA3, patatin like phospholipase domain containing 3; SNP, single nucleotide polymorphism; T1D, type 1 diabetes; T2D, type 2 diabetes.

\section{Introduction}

The North is a multicomponent extreme factor for humans and has a multifaceted negative impact on the human body by a specific production and environmental component, causing a number of changes in the metabolism and functional activity of all body systems and changing a body's need for energy, food and biologically active food components.

*Corresponding author: Lubov A. Sydykova, PhD. M. K. Ammosov North-Eastern Federal University, Yakutsk, the Republic of Sakha (Yakutia),Russia. E-mail: borinat@yandex.ru
The indigenous population of the North is characterized by a protein-lipid type of nutrition, which contributes to the formation of a "polar metabolic type." This type of nutrition is characterized by a high content of protein in the daily diet (15\% and more), fat (35\% and more), carbohydrates (50\% and less), in contrast to the "European type," in which carbohydrates predominate. In the diet of a person living in the Far North, the energy role of carbohydrates is reduced and the role of fats, and to a lesser extent of proteins, is increased, thus forming the so-called "polar metabolic type." In the indigenous inhabitants of the North, the energy metabolism switches from carbohydrate type to fatty type, lipid metabolism increases due to food sources of fat, and lipid metabolism increases due to 
food sources of fat, that is, rapid "combustion" of exogenous and not endogenous fat. This is why aborigines can consume more meat and fat (the Eskimo, for example, can eat $6-8 \mathrm{~kg}$ of meat per day). Therefore, the indigenous people of the North, engaged in traditional northern types of management, rarely suffer from CVD, in contrast to sedentary aborigines living in settlements and students in boarding schools, who are forced to consume large amounts of carbohydrates. Thus, increasing globalization has led to a change in nutrition of the indigenous inhabitants of the northern regions and an increase in metabolic diseases and T2D. ${ }^{(1)}$

Epidemiological data indicate the frequent combination of T2D and NAFLD characterized by an accumulation of lipids both in the hepatocytes themselves and in the intercellular space. ${ }^{(2)} \mathrm{T} 2 \mathrm{D}$ patients are characterized by insulin resistance, and often have obesity, dyslipidemia and increased activity of hepatic enzymes. For these patients, there is a tendency to accumulate fat in the liver, which causes a higher risk of developing severe liver pathology compared to patients without T2D. ${ }^{(3)}$

Studies in recent years prove the hereditary mechanisms of the development of NAFLD. A genome-wide association study of a multiethnic population found that a single rs738409 $\mathrm{C}>\mathrm{G}$ polymorphism of the PNPLA3 gene, which encodes $\mathrm{I} 148 \mathrm{M}$, is strongly associated with hepatic fat content and conferred susceptibility to NAFLD. ${ }^{(4,5)}$

PNPLA3 is expressed in the liver and adipose tissue and has acyl hydrolase activity.(6) The PNPLA3 protein exhibits lipase activity against triglycerides and acylglycerol transacetylase activity, and its expression is highly responsive in energy mobilization and the storage of lipid droplets. ${ }^{(7)}$ In humans, the PNPLA3 I148M mutation has been shown to influence not only intrahepatic remodeling but also reduces very low density lipoproteins secretion. ${ }^{(8)}$

Recently, a study showed that carriers of the rs $738409[\mathrm{G}]$ allele have lower de novo lipogenesis as compared to noncarriers due to a reduction in liver SREBP1c mRNA levels..$^{(9)}$ The reduction in hepatic de novo lipogenesis may be interpreted as a compensatory effect of hepatic fat increase.

The rs738409 polymorphism has been associated with the loss of the protein's hydrolyzing function and with the hepatic triglyceride accumulation. ${ }^{(6)}$ The rs738409 polymorphism is strongly associated with steatosis, fibrosis/ cirrhosis in various liver diseases with different etiologies (NAFLD, ALD, CHC, HCC). ${ }^{(10-15)}$

The purpose of our research was to study the association of the PNPLA3 SNP rs738409 (C>G) with T2D in the Yakuts.

\section{Materials and Methods}

Molecular genetic studies were conducted in the molecular genetics department at YSC CMP. DNA samples were obtained from the YSC CMP biomaterial collection ("Genome of Yakutia", registration No. USU_507512).

The study included 106 patients (79 women and 27 men) of the Yakut nationality aged between 31 to 82 years (mean age, $60.7 \pm 0.42$ yrs) with T2D (Group 1). The comparison group consisted of 72 healthy volunteers ( 24 men and 48 women aged between 19 and 55 years, mean age of $28.2 \pm 0.49 \mathrm{yrs}$ ) (Group 2). All participants in the study were of Yakut ethnicity and lived in the territory of the Republic of Sakha (Yakutia) [the $\mathrm{RS}(\mathrm{Y})$ ]. Exclusion criteria were the following: chronic viral hepatitis, autoimmune hepatitis, primary biliary cholangitis, primary sclerosing cholangitis, hereditary hemochromatosis, Wilson-Konovalov disease, alcohol abuse ( $>30 \mathrm{~g} / \mathrm{l})$.

Genomic DNA was extracted from peripheral blood were conducted using the phenol-chloroform standard method. After DNA extraction, the samples were subjected to a PCRRFLP reaction to analyze the rs738409 polymorphism of the PNPLA3 gene where the homozygous wild type CC genotype (200 and $133 \mathrm{bp}$ ), the heterozygous genotype is CG (333, 200 and $133 \mathrm{bp}$ ) and the homozygous mutanttype GG genotype (333 bp). The following primers were used: F: 5'-TGGGCCTGAAGTCCGAGGGT-3' and R: 5'-CCGACACCAGTGCCCTGCAG-3' (Biotech Industry Ltd, Moscow, Russia). The reaction mixture $(25 \mu \mathrm{L})$ contained $13 \mu \mathrm{l}$ of ddH2O, $2.5 \mu \mathrm{l}$ 10xPCR buffer, $2.5 \mu 125 \mathrm{mM} \mathrm{MgCl} 2,2.5 \mu \mathrm{l}$ $2.5 \mathrm{mM}$ dNTP Mix, $1,5 \mu \mathrm{l}(10 \mathrm{pkmol} / \mu \mathrm{l})$ of each oligonucleotide primer, 0.3 ul (1.5 units.) "hotstart" Taq-polymerase and 3 $\mu 1$ of DNA. PCR amplification was carried out in the MJ Mini Gradient Thermal Cycler (Bio-Rad). Thermal Cycling Conditions were as follows: $95^{\circ} \mathrm{C}$ for $5 \mathrm{~min}$, and then 37 cycles at $94^{\circ} \mathrm{C}$ for $30 \mathrm{sec}$, at $66^{\circ} \mathrm{C}$ for $30 \mathrm{sec}$, and at $72{ }^{\circ} \mathrm{C}$ for $40 \mathrm{sec}$ and a final elongation at $72^{\circ} \mathrm{C}$ for 5 minutes.

To determine the rs738409 (C>G) polymorphism genotype, the restriction endonuclease BstF5 I (SibEnzyme, Novosibirsk, Russia) was used (at 65 for 16 hours). The products of the restriction enzyme digestion were subjected to electrophoresis in a $1.5 \%$ agarose gel in a horizontal electrophoretic tank containing TBE buffer (1X concentration) with a constant current of $120 \mathrm{~V}$ for 1 hour. The resulting bands were visualized under ultraviolet (UV) light using a gel documentation system (Vilber Lourmat, France) (Figure 1). The images were recorded to digital files.

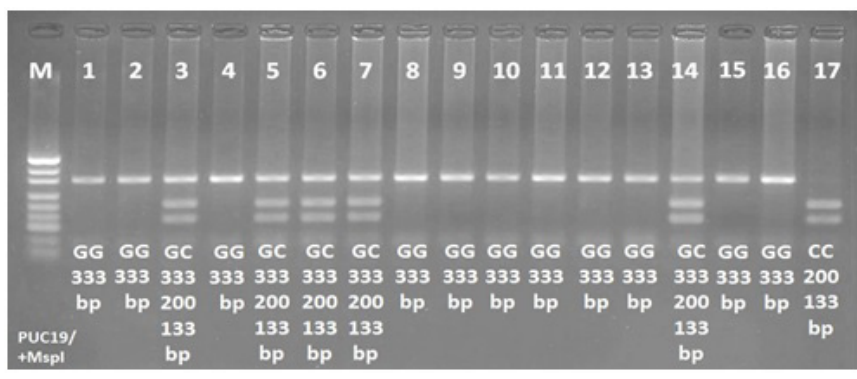

Fig. 1. Electropherogram representing PCR amplification product of the PNPLA3 SNP rs $738409(C>G)$

Statistical analysis was performed using the Statistica 8.0 software package (StatSoft Inc, USA). The chi-square test was used to determine the deviation from Hardy-Weinberg equilibrium (HWE) and the differences in genotypes and alleles between groups. The expected heterozygosity $(\mathrm{He})$ was calculated using the Nei (1987) estimator. A probability value of $P<0.05$ was considered statistically significant.

The study was approved by our regional ethics committee. Written informed consent was obtained from all patients. 
Table 1.

Prevalence and incidence of endocrine pathology per 1,000 population in $R S(Y)$

\begin{tabular}{|l|c|c|c|c|c|c|c|c|c|c|c|c|}
\hline \multirow{2}{*}{ Endocrine pathology } & \multicolumn{5}{|c|}{ Prevalence of disease per 1000 population } & \multicolumn{3}{c|}{ Incidence of disease per 1,000 population } \\
\cline { 2 - 15 } & 2006 & 2008 & 2010 & 2012 & 2014 & 2016 & 2006 & 2008 & 2010 & 2012 & 2014 & 2016 \\
\hline $\begin{array}{l}\text { Endocrine system } \\
\text { diseases }\end{array}$ & 80.3 & 82.4 & 82.04 & 87.2 & 89.0 & 89.3 & 12.8 & 14.5 & 15.6 & 14.7 & 14.9 & 15.8 \\
\hline DM (total) & 20.4 & 22.6 & 30.88 & 30.41 & 32.3 & 33.9 & 2.6 & 2.9 & 3.2 & 3.8 & 3.9 & 4.0 \\
\hline T1D & 1.83 & 1.83 & 2.4 & 0.77 & 0.80 & 0.85 & 0.1 & 0.2 & 0.2 & 0.1 & 0.1 & 0.1 \\
\hline T2D & 19.1 & 20.3 & 28.0 & 29.2 & 28.8 & 29.45 & 2.4 & 2.8 & 3.1 & 3.2 & 3.4 & 3.6 \\
\hline Thyroid diseases & 26.8 & 27.8 & 27.8 & 29.2 & 28.8 & 28.6 & 6.8 & 7.8 & 7.8 & 9.2 & 8.8 & 8.2 \\
\hline Hypothyroidism & 9.2 & 8.8 & 9.46 & 9.6 & 9.8 & 9.4 & 1.12 & 1.15 & 1.20 & 1.25 & 1.33 & 1.38 \\
\hline Thyrotoxicosis & 6.5 & 6.4 & 6.8 & 6.6 & 6.9 & 7.2 & 0.6 & 0.7 & 0.8 & 0.8 & 0.93 & 0.97 \\
\hline Obesity & 20.3 & 22.3 & 28.7 & 29.9 & 38.8 & 39.45 & 2.3 & 2.7 & 3.4 & 3.7 & 3.9 & 4.2 \\
\hline
\end{tabular}

\section{Results and Discussion}

Currently in Yakutia, the morbidity incidence caused by endocrine pathology tends to increase, primarily due to the growth of diabetes and obesity (Table 1). In RS(Y), the total morbidity rate caused by endocrine pathology is 89.3 per 1000 population and the level of newly diagnosed endocrine pathology is 15.8 per 1000 population. On average, about $8 \%$ of the population of the $\mathrm{RS}(\mathrm{Y})$ are on prophylactic medical examination for endocrine pathology. In Aldan (industrial area) and Allayhovsky (arctic region) districts, these indicators are higher than the average values for the republic

The prevalence of $\mathrm{DM}$ in $\mathrm{RS}(\mathrm{Y})$, according to the Online Diabetes Registry for the period from 2013 to 2016, amounted to $15 \%$, with an annual increase of $3.5 \%-6.85 \%$. In DM patients, the need for medical assistance increases with the deterioration of their condition and the occurrence of complications. The prevalence of vascular complications of DM remains high, including diabetic retinopathy, diabetic nephropathy, and cardiovascular complications. In the RS(Y), the proportion of complications of DM is (according to data at the end of 2016) $35.57 \%$ for T1D and $30.2 \%$ for T2D. The average life expectancy of T1D patients is 47.5 years for men and 45.67 years for women; in T2D - 63.59 for men and 67.54 years for women. Mortality from DM in the RS(Y) is 24.17 per 100,000 population.

In clinical practice, the high risk of coexistence of NAFLD and DM should be considered. The prevalence of NAFLD in the general population of Western countries is 20$30 \%$ and among obese adults it is $80 \%-90 \% .{ }^{(16)}$ The prevalence of NAFLD is remarkably increased in patients with T2D, ranging from $30 \%$ to $75 \%$ according to age, ethnicity, the study population and the diagnostic tools used..$^{(17)}$

NAFLD is defined as either excessive fat accumulation in the liver with more than $5 \%$ of hepatocytes containing visible intracellular triglycerides or steatosis affecting at least $5 \%$ of the liver volume or weight in patients consuming less than $30 \mathrm{~g}$ of alcohol per day for men and less than $20 \mathrm{~g}$ of alcohol per day for women. ${ }^{(18-20)}$

The frequency distribution of alleles and genotypes of the PNPLA3 SNP rs738409 was in accordance with HWE. There were no statistically significant differences in the distribution of alleles and genotypes of the PNPLA3 SNP rs738409 $(\mathrm{C}>\mathrm{G})$ between Group 1 and Group $2(P>0.05)$; the $\mathrm{G}$ allele and homozygous GG genotype prevailed in both groups. Population-genetic analysis among the Yakuts on the PNPLA3 SNP rs738409 (C>G) showed that the level of observed heterozygosity (Ho) in T2D patients was 0.311 ; in healthy individuals $\mathrm{Ho}=0.319$. The level of the expected heterozygosity $(\mathrm{He})$ in T2D patients was 0.387 , in healthy individuals $\mathrm{He}=0.395$. The genotype frequencies of the PNPLA3 rs738409 (C>G) SNP are presented in Table 2.

According to the 1000 Genomes Project data, the frequency of the PNPLA3 (rs738409) G allele in different populations is characterized by heterogeneity.

Table 2.

Genotype and allele distribution of the PNPLA3 SNP rs 738409 in the groups

\begin{tabular}{|c|c|c|c|c|c|c|c|c|c|c|}
\hline \multirow{2}{*}{ Group } & & \multicolumn{3}{|c|}{ Genotype, \% } & \multicolumn{2}{|c|}{ Allele } & \multirow{2}{*}{$\chi^{2}$} & \multirow{2}{*}{$\mathrm{H}_{\mathrm{o}}$} & \multirow{2}{*}{$\mathrm{H}_{\mathrm{e}}$} & \multirow{2}{*}{$\mathrm{P}$} \\
\hline & & $\mathrm{CC}$ & GC & GG & $\mathrm{C}$ & G & & & & \\
\hline \multirow[b]{2}{*}{ Group 1} & Obs. & 10.38 & 31.13 & 58.49 & \multirow[b]{2}{*}{0.259} & \multirow[b]{2}{*}{0.741} & \multirow[b]{2}{*}{4.123} & \multirow[b]{2}{*}{0.311} & \multirow[b]{2}{*}{0.387} & \multirow[b]{2}{*}{0.05} \\
\hline & Exp. & 6.71 & 38.38 & 54.91 & & & & & & \\
\hline \multirow{2}{*}{ Group 2} & Obs. & 11.11 & 31.94 & 56.94 & \multirow{2}{*}{0.271} & \multirow{2}{*}{0.729} & \multirow{2}{*}{2.632} & \multirow{2}{*}{0.319} & \multirow{2}{*}{0.395} & \multirow{2}{*}{0.105} \\
\hline & Exp. & 7.34 & 39.50 & 53.17 & & & & & & \\
\hline
\end{tabular}


The frequency of $\mathrm{G}$ allele of the PNPLA3 SNP rs738409 in T2D patients and healthy volunteers of Yakut nationality prevails in comparison with other populations. Thus, in T2D patients, a high frequency of the $\mathrm{G}$ allele $(74.1 \%)$ was found, with a predominance of the GG genotype $(58.5 \%)$. In study by JM Patit et al., the frequencies of $\mathrm{G}$ and $\mathrm{C}$ alleles of the PNPLA3 SNP rs738409 in T2D patients of the France's population were 29.6 and $70.4 \%$, respectively. ${ }^{(21)}$ According to A. J. Cox, the lowest frequency of the $\mathrm{G}$ allele (13.7\%) with the GG genotype frequency of $1.5 \%$ was found in African American patients with T2D. ${ }^{(22)}$

C. Huang et al. showed that the PNPLA3 genetic variants were associated with advanced liver fibrosis in diabetic patients only, but not in non-diabetic patients. The PNPLA3 gene was the most important predictive factor of bridging fibrosis in diabetic patients, using the recessive model (OR: 4.53, CI: 1.356-15.106, $P=0.014$ ) or the dominant model (OR: 2.20, CI: $1.026-4.734, P=0.04)$. Compared to non-diabetic patients, patients with the diabetes/GG genotype were more likely to have advanced liver fibrosis (OR: 8.79, CI: 2.889-26.719, $P<0.001$ ), followed by those with diabetes/non-GG genotype (OR: 1.55, CI: 1.048-2.286, $P=0.03$ ). ${ }^{(23)}$

In study by R. Posadas-Sánchez et al., the I148M/PNPLA3 (rs738409) polymorphism was associated with the presence of premature coronary artery disease in T2DM patients and with some cardiometabolic parameters. ${ }^{(24)}$

However, a number of studies indicate that there is no straightforward association between PNPLA3 and insulin action or glucose homeostasis metabolism. ${ }^{(25,26)}$

As noted by many domestic and foreign researchers, carriers of the PNPLA3 G allele are more susceptible to liver diseases (NAFLD, NASH) with a high risk of developing cirrhosis and HCC. ${ }^{(4)}$ Patients with T2D and NAFLD have a higher risk of CVD, as well as mortality, due to the depletion of hepatic glycogen stores and a decrease in the reserve regulation capacity of glucose homeostasis with the accelerated development of vascular complications. At the same time, fatty hepatosis, regardless of the cause, can contribute to high insulin levels due to reduced insulin clearance. ${ }^{(21)}$

Undoubtedly, further studies with larger sample size are required to achieve sufficient statistical power to detect the association of the PNPLA3 SNP rs738409 SNP with the development of T2D in Yakut patients.

\section{Competing interests}

The authors declare that they have no competing interests.

\section{References}

1. Dedov II, Shestakova MV, Vikulova OK. [Epidemiology of diabetes mellitus in Russian Federation: clinical and statistical report according to the federal diabetes registry]. Diabetes mellitus. 2017;20(1):13-41. doi: 10.14341/DM8664. [Article in Russian].

2. Biryukova EV, Rodionova SV. [Type 2 diabetes mellitus and non-alcoholic fatty liver disease - diseases of modern times]. Medical Almanac. 2017;(6):130-5. [Article in Russian]. 3. EASL-EASD-EASO Clinical Practice Guidelines for the management of non-alcoholic fatty liver disease. European Association for the Study of the Liver (EASL); European Association for the Study of Diabetes (EASD); European Association for the Study of Obesity (EASO). J Hepatol. 2016;64(6):1388-402. doi: 10.1016/j.jhep.2015.11.004.

4. Romeo S, Kozlitina J, Xing C, Pertsemlidis A, Cox D, Pennacchio LA, et al. Genetic variation in PNPLA3 confers susceptibility to nonalcoholic fatty liver disease. Nat Genet. 2008;40(12):1461-5. doi: 10.1038/ng.257

5. Zhang L, You W, Zhang H, Peng R, Zhu Q, Yao A, et al. PNPLA3 polymorphisms (rs738409) and non-alcoholic fatty liver disease risk and related phenotypes: a meta-analysis. J Gastroenterol Hepatol. 2015;30(5):821-9. doi: 10.1111/ jgh.12889.

6. Huang Y, Cohen JC, Hobbs HH. Expression and characterization of a PNPLA3 protein isoform (I148M) associated with nonalcoholic fatty liver disease. J Biol Chem. 2011;286(43):37085-93. doi: 10.1074/jbc.M111.290114.

7. Sookoian S, Pirola CJ. PNPLA3, the triacylglycerol synthesis/hydrolysis/storage dilemma, and nonalcoholic fatty liver disease. World J Gastroenterol. 2012;18(42):6018-26. doi: 10.3748/wjg.v18.i42.6018.

8. Pirazzi C, Adiels M, Burza MA, Mancina RM, Levin M, Stahlman M, et al. Patatin-like phospholipase domain-containing 3 (PNPLA3) I148M (rs738409) affects hepatic VLDL secretion in humans and in vitro. J Hepatol. 2012;57(6):1276-82. doi: 10.1016/j.jhep.2012.07.030.

9. Mancina RM, Matikainen N, Maglio C, Soderlund S, Lundbom N, Hakkarainen A, et al. Paradoxical dissociation between hepatic fat content and de novo lipogenesis due to PNPLA3 sequence variant. J Clin Endocrinol Metab. 2015;100(5):E821-5. doi: 10.1210/jc.2014-4464.

10. Trépo E, Romeo S, Zucman-Rossi J, Nahon P. PNPLA3 gene in liver diseases. J Hepatol. 2016;65(2):399-412. doi: 10.1016/j.jhep.2016.03.011.

11. Valenti L, Al-Serri A, Daly AK, Galmozzi E, Rametta $\mathrm{R}$, Dongiovanni $\mathrm{P}$, et al. Homozygosity for the patatin-like phospholipase-3/adiponutrin I148M polymorphism influences liver fibrosis in patients with nonalcoholic fatty liver disease. Hepatology 2010;51(4):1209-17. doi: 10.1002/hep.23622.

12. Trépo E, Gustot T, Degre D, Lemmers A, Verset L, Demetter P, et al. Common polymorphism in the PNPLA3/ adiponutrin gene confers higher risk of cirrhosis and liver damage in alcoholic liver disease. J Hepatol. 2011;55(4):90612. doi: 10.1016/j.jhep.2011.01.028.

13. Valenti L, Rumi M, Galmozzi E, Aghemo A, Del Menico B, De Nicola S, et al. Patatin-like phospholipase domaincontaining 3 I148M polymorphism, steatosis, and liver damage in chronic hepatitis C. Hepatology 2011;53(3):791-9. doi: 10.1002/hep.24123.

14. Muller T, Buch S, Berg T, Hampe J, Stickel F. Distinct, alcohol-modulated effects of PNPLA3 genotype on progression of chronic hepatitis C. J Hepatol. 2011;55(3):732733. doi: 10.1016/j.jhep.2011.01.025.

15. Trépo E, Pradat P, Potthoff A, Momozawa Y, Quertinmont $\mathrm{E}$, Gustot $\mathrm{T}$, et al. Impact of patatin-like phospholipase-3 (rs738409 $\mathrm{C}>\mathrm{G}$ ) polymorphism on fibrosis progression and steatosis in chronic hepatitis C. Hepatology. 2011;54(1):60-9. doi: 10.1002/hep. 24350 .

16. Bellentani S, Scaglioni F, Marino M, Bedogni G. Epidemiology of non-alcoholic fatty liver disease. Dig Dis. 2010;28(1):155-61. doi: 10.1159/000282080.

17. Lonardo A, Bellentani S, Argo CK, Ballestri S, Byrne 
$\mathrm{CD}$, Caldwell SH, et al.. Epidemiological modifiers of nonalcoholic fatty liver disease: Focus on high-risk groups. Dig Liver Dis. 2015;47(12):997-1006. doi: 10.1016/j. dld.2015.08.004.

18. Abd El-Kader SM, El-Den Ashmawy EM. Non-alcoholic fatty liver disease: The diagnosis and management. World J Hepatol. 2015;7(6):846-858. doi: 10.4254/wjh.v7.i6.846

19. McCullough AJ. Pathophysiology of nonalcoholic steatohepatitis. J Clin Gastroenterol. 2006;40 Suppl 1:S17-29. 20. Serfaty L, Lemoine M. Definition and natural history of metabolic steatosis: clinical aspects of NAFLD, NASH and cirrhosis. Diabetes Metab. 2008;34(6 Pt 2):634-7. doi: 10.1016/S1262-3636(08)74597-X.

21. Petit JM, Guiu B, Masson D, Duvillard L, Jooste V, Buffier P, et al.. Specifically PNPLA3-mediated accumulation of liver fat in obese patients with type 2 diabetes. J Clin Endocrinol Metab. 2010;95(12):E430-6. doi: 10.1210/jc.2010-0814.

22. Cox AJ, Wing MR, Carr JJ, Hightower RC, Smith SC, $\mathrm{Xu}$ J, et al. Association of PNPLA3 SNP rs738409 with liver density in African Americans with type 2 diabetes mellitus. Diabetes Metab. 2011;37(5):452-5. doi: 10.1016/j. diabet.2011.05.001.
23. Huang CF, Dai CY, Yeh ML, Huang CI, Tai CM, Hsieh $\mathrm{MH}$, et al. Association of diabetes and PNPLA3 genetic variants with disease severity of patients with chronic hepatitis C virus infection.J Hepatol. 2015 Mar;62(3):512-8. doi: 10.1016/j.jhep.2014.10.011.

24. Posadas-Sánchez R, López-Uribe ÁR, Posadas-Romero C2, Pérez-Hernández N3, Rodríguez-Pérez JM, OcampoArcos WA, et al. Association of the I148M/PNPLA3 (rs738409) polymorphism with premature coronary artery disease, fatty liver, and insulin resistance in type 2 diabetic patients and healthy controls. The GEA study.Immunobiology. 2017;222(10):960-966. doi: 10.1016/j.imbio.2016.08.008.

25. Kantartzis K, Peter A, Machicao F, Machann J, Wagner S, Konigsrainer I, et al. Dissociation between fatty liver and insulin resistance in humans carrying a variant of the patatinlike phospholipase 3 gene. Diabetes. 2009;58(11):2616-2623. doi: $10.2337 / \mathrm{db} 09-0279$.

26. Speliotes EK, Butler JL, Palmer CD, Voight BF; GIANT Consortium; MIGen Consortium; NASH CRN, Hirschhorn JN. PNPLA3 variantsspecifically confer increased risk for histologic nonalcoholic fatty liver disease but not metabolic disease. Hepatology. 2010;52:904-912. doi: 10.1002/hep.23768. 